\title{
Impact of the 'Seguro Médico Siglo XXI' medical insurance programme on neonatal and infant mortality in Mexico, 2006-14: an ecological approach to estimation
}

\author{
José Urquieta-Salomón ${ }^{1}$, Héctor Lamadrid-Figueroa (1) ${ }^{2, *}$, \\ Gustavo Angeles ${ }^{3}$, Alejandra Montoya ${ }^{2}$, Rosalba Rojas-Martínez ${ }^{2}$, \\ Alejandro Martínez-Nolasco ${ }^{2}$, Pilar Torres-Pereda ${ }^{2}$, Gabriel O'Shea ${ }^{4}$, \\ Victor M Villagrán ${ }^{5}$, Elizabeth Halley ${ }^{5}$, Verónica Delgado-Sánchez ${ }^{5}$ and \\ Eduardo Lazcano-Ponce ${ }^{2}$
}

${ }^{1}$ Directorate of Indicators and Analysis of Governmental Information, National Institute of Statistics and Geography, Av. Patriotismo 711A, Benito Juárez, 03730, Ciudad de México, México, ${ }^{2}$ Department of Perinatal Health, National Institute of Public Health (INSP), Av. Universidad 655, 62440, Cuernavaca, MOR, Mexico, ${ }^{3}$ Department of Maternal and Child Health, Gillings School of Global Public Health, University of North Carolina at Chapel Hill, 135 Dauer Dr, Chapel Hill, NC 27599, USA, ${ }^{4}$ Secretaría de Salud del Estado de México, Av. Independencia 5 Ote. 1009, Reforma y FFCC Nacionales, 50070 Toluca de Lerdo, México, and ${ }^{5}$ Comisión Nacional de Protección Social en Salud, Secretaría de Salud, Calle Gustavo E. Campa 54, Guadalupe Inn, Álvaro Obregón, 01020 Ciudad de México, CDMX, México

*Corresponding author. Department of Perinatal Health, National Institute of Public Health (INSP), Av. Universidad 655, 62440, Cuernavaca, MOR, Mexico. E-mail: hlamadrid@insp.mx

Accepted on 31 January 2020

\begin{abstract}
The 'Seguro Médico Siglo XXI' (SMSXXI), a universal coverage medical insurance programme for children under 5 years of age, started in 2006 to help avoid catastrophic health expenditures in poor families without social security in Mexico. The study used information from the National Health Information System for the 2006-14 period. An ecological approach was followed with a panel of the 2457 municipalities of Mexico as the units of analysis. The outcome variables were the municipalitylevel neonatal mortality and infant mortality rates in population without access to social security. The programme variable was the coverage of the SMSXXI programme at the municipality level, expressed as a proportion. Demographic and economic variables defined at the municipality level were included as covariates. Impact was estimated by fitting a fixed-effects negative binomial regression model. Results reveal that the SMSXXI significantly reduced both infant and neonatSal mortality in the target population, although in a non-linear fashion, with minimum mortality levels found around the $70 \%$ coverage range. The effect is mostly given by the transition from the first quintile to the fourth quintile of coverage ( $<13 \%$ vs $70.5-93.7 \%$ coverage), and it is attenuated significantly at coverage levels very close to or at $100 \%$. The observed risk reduction amounted to an estimated total of 11358 infant deaths being avoided due to the SMSXXI during the 2006-14 period, of which $48 \%$ were neonatal. In conclusion, we found a significant impact of the SMSXXI programme on both infant mortality and neonatal mortality. An attenuation of the effect of the insurance on mortality rates at levels close to $100 \%$ coverage may reflect the saturation of health units in detriment of the quality of care.
\end{abstract}

Keywords: Neonatal mortality, infant mortality, impact evaluation, Mexico, medical insurance 


\section{Key Messages}

- The XXI Century Medical Insurance, a medical insurance scheme for children under 5 years of age, was implemented in Mexico in 2009; so far no evaluation of its impact on mortality has been put forward.

- The insurance had a modest but significant impact on both neonatal and infant mortality reduction; however, the largest impact is observed at coverage levels $\sim 70 \%$ with a smaller effect at levels closer to $100 \%$, raising concerns of an insufficient capacity to meet increased demands.

\section{Introduction}

Children represent approximately one-third of the world's population. Despite the fact that most of causes of death and morbidity are preventable or treatable with currently available interventions, they are the age group most vulnerable to loss of health (WHO, 2018).

Over time, the reduction in the under- 5 mortality rate has been considered as an important progress indicator to assess progress towards global development goals. Millennium Development Goal 4 targeted a reduction in child mortality by two-thirds from 1990 to 2015. At the end of the period, substantial global progress had been made and the number of under-5 deaths worldwide declined from 11 million in 1990 to 5.2 million in 2015 (IHME, 2016); however, only 58 countries met or exceeded the pace of progress required. For most of the low- and middle-income countries (such as Mexico), the decline in neonatal mortality was slower than that in all under-5 deaths and, thus, the proportion of child deaths that occur in the neonatal period has increased (GBD 2015 Child Mortality Collaborators, 2016). Mexico's under-5 deaths fell from 114000 in 1990 to 37000 in 2015, which represents a reduction of $64.7 \%$ in the under- 5 mortality rate, while neonatal mortality rate reduction in the same period was only $53 \%$.

The first 28 days of life-the neonatal period-represent the most vulnerable time for a child's survival (WHO, 2018). In 2016, 5 million children under 5 years of age died, of whom 2.1 million died during the first 28 days of life; $78 \%$ of these neonatal deaths occurred in the first week (IHME, 2016). In Mexico, 35500 deaths of children under 5 years of age occurred, $\sim 50 \%$ of these during the first 28 days of life. As a response, current global efforts to meet the Sustainable Development Goals emphasize reducing neonatal deaths.

In December 2006, the Mexican government created the thencalled Medical Insurance for a New Generation [Seguro Médico para una Nueva Generación (SMNG, acronym in Spanish)], which changed its name to XXI Century Medical Insurance [Seguro Médico Siglo XXI (SMSXXI, acronym in Spanish)] in 2013. This insurance was designed to lessen the incidence of catastrophic expenditure due to health issues of children under 5 years of age without social security, and born no earlier than 1 December 2006. The programme has contributed to finance medical care of children without social security, providing at the same time immediate affiliation of the whole family to the Social Health Protection System (SPSS, acronym in Spanish), widely known as 'Seguro Popular'. Medical Insurance of children is achieved through the financing of actions performed at the first, second or third level of care, which are included either in the Rules of Operation of SMSXXI, the Universal Catalog of Essential Health Services or the Catastrophic Expenditure Protection Fund of the SPSS (CAUSES, 2019; Comision Nacional de Protección en Salud, 2019a,b). Insurance plans protect the family against impoverishing due to out-of-pocket expenditures due to illnesses suffered by their children, provided this is included in either of the above lists. The programme also promotes hospitals to invest in equipment and human resources, thereby increasing the quality of care.

According to the official information, the SMSXXI covered a total of 5649647 million children under 5 years of age in 2014 . Since its introduction in 2006 as the SMNG, coverage expanded significantly until 2012, when adjustments to the rules of operation were made and children $>5$ years of age went to be enrolled in the 'Seguro Popular'. In 2019, the SMSXXI covered nearly all of its target population, which was well above the affiliation objective proposed by the programme, especially considering that affiliation was voluntary. According to its rules of operation as of 2014, there were no specific focalization criteria beyond being children under 5 years of age without social security. Nevertheless, according to the survey performed in 2009 to evaluate the SMNG, $72 \%$ of the affiliated children resided in urban areas.

Two plausible pathways to impact are increased the utilization of health services and an increase in the quality of care, which are expected as intermediate effects of the programme. Despite several attempts at evaluating the performance, consistency and results of the SMSXXI, few evaluations of its bearing on health outcomes have been put forward. Pfutze (2014) had estimated in 2010 that the 'Seguro Popular' programme was expected to reduce infant mortality by up to 5 avoided deaths per 1000 live births. Specifically discussing on SMSXXI, Reyes-Lopez commented on the potential of SMSXXI to positively influence mortality, citing work put forth by Flores-Huerta et al. who found a relation between out-of-pocket health expenditure and infant mortality (Flores-Huerta et al., 2014; Reyes-López, 2014).

The aim of this study was to evaluate the overall impact of the SMSXXI programme on neonatal and infant mortality rates in population without access to social security. We propose to do that by examining the link between the variations in coverage to the variations in mortality rates at the municipality level in Mexico using data from health and economic information systems, controlling for trends in covariates related to socio-economic factors and access to health services.

\section{Materials and methods}

\section{Data sources and collection}

The study used vital statistics information from the National Health Information system (SINAIS, acronym in Spanish). From the SINAIS datasets, we obtained information on births by the municipality of residence as well as socio-economic characteristics of the mothers, deaths, human resources in health and health infrastructure, as well as municipal projections for population with and without social security. In particular, information on live births by the condition of access to social security was obtained from the Birth Information subsystem of the Secretariat of Health. From INEGI datasets, we obtained information on demographic and geographic 
characteristics of municipalities, as well as economic and education variables.

Information on numbers of SMSXXI affiliates at the municipality level was directly provided by the National Commission for Health Protection, the SMSXXI implementer agency. Estimates of the number of children under 5 years of age without access to social security, used as the denominator for insurance coverage rates, were obtained from the National Population Council (CONAPO, acronym in Spanish). Data on the number of beneficiary families in the Oportunidades/PROSPERA programme at the municipal level were obtained from publicly available data by the Mexican government.

\section{Variable definitions}

Population was obtained in the following way: for years 2006-09, estimates were generated as an interpolation of information of the 2005 and 2010 censuses and, for the rest of the years, population estimates by CONAPO were used. Municipal population density was defined as the total population of a municipality in a particular year divided by its area. Birth data were identified by municipality and classified by the type of Social Security provider.

Women's characteristics were obtained from the birth datasets, and rates were generated on schooling (primary, secondary, high school, bachelor studies, graduate studies) and mother's age $(<20$, $20-34,>34)$. In the same manner, we identified remunerated activities as follows: non-remunerated (unoccupied, domestic work, student, retired); remunerated (professional work, technical work, education, art, entertainment and sports, state workers, private directive personnel, agriculture, animal raising, hunting, fishing, masonry, commerce, personal services, etc.); and unspecified occupations. Regarding deaths by the municipality of residence, we obtained data on deaths occurred to children without social security, which constitute the target population of the insurance. Within these, we identified deaths in children under 1 year of age and under 28 days of age. We also obtained data on health infrastructure such as the number of hospitals and outpatient clinics. In addition, we obtained data on human resources such as the total number of doctors and nurses in contact with patients.

Variables on educational characteristics of each of the municipalities were obtained from the INEGI-SIMBAD datasets. These were: total number of students and promoted students in basic and secondary education; number of teachers in basic, secondary and tertiary education; number of basic education schools; and number of classrooms in basic education schools.

The level of coverage of the SMSXXI was calculated by dividing the number of beneficiaries in the $i$ th municipality in the $t$ th year with respect to the population without access to social security of 0 4 year olds. In cases where the number of affiliates was greater than the estimated target population of the municipality, coverage was truncated at $100 \%$.

\section{Statistical analysis}

\section{Impact estimation}

Causes of neonatal and infant mortality are not just related to deficiencies in the institutional response to health risks in minors but also related to structural factors such as poverty, child rearing and restrictions to access to goods such as food (PAHO, 2008). To account for these factors, the analysis included a series of municipality-level covariates and fixed effects; the latter strategy allows us to capture unobservable heterogeneity that remains more or less constant in time and bears an influence on mortality rates. These fixed characteristics are frequently associated with socio- cultural factors such as adult schooling rates, poverty levels or idiosyncratic aspects of behaviour.

As a potential relationship between coverage and mortality is presumably non-linear, a first approach to impact estimation was using the fractional polynomial model methodology proposed by Royston and Sauerbrei (2008). In brief, the fractional polynomial approach is an alternative to regular polynomials that provides flexible parameterization for continuous variables and allows for nonlinear effects to be modelled.

The empirical specification was of the form:

$$
\operatorname{Ln}\left(y_{i t}\right)=\alpha+\beta_{1} s_{i t}^{(p 1)}+\beta_{2} s_{i t}^{(p 2)}+\beta_{3} t_{t}+\beta_{4} t_{t}^{2}+X_{i t} \gamma+\mu_{i}+\varepsilon_{\mathrm{it}},
$$

where $\operatorname{Ln}\left(y_{i t}\right)$ denotes the natural log of the neonatal or infant mortality rate of the $i$ th municipality in the $t$ th year; the denominator of the mortality rate (exposure) is the number of births without social security; the numerator is the number of deaths in children without social security; $s$ represents the insurance coverage in the $i$ th municipality in the $t$ th year; $p 1$ and $p 2$ represent powers to be searched that can take the values: $-2,-1,-0.5,0,0.5,1,2$ and $3 ; X_{i t}$ denotes a vector of covariates; $\mu_{i}$ are time-invariant unobservable fixed variables; and $\varepsilon_{i t}$ represents unobserved time-variable factors that are assumed to be random. Covariates were: municipality population density, age distribution and rates of occupation and schooling of the mothers of newborns in the $i$ th municipality on the $t$ th year, number of medics in contact with patients and number of nurses in contact with patients; to avoid assuming linearity, all covariates were included as quintile categories. To control for the secular trend of mortality, calendar time was included as a second-degree regular polynomial. For the ease of interpretation and to make for a straight-forward calculation of avoided deaths (ADs) attributable to SMSXXI, we fitted a second model in which yearly municipality observations of coverage were classified into quintiles.

As it is to be expected that $\mu_{i}$ are related not only with $y_{i t}$ but also with the rest of the variables in the model, the models were estimated through a negative binomial regression using a fixed-effects or 'within estimator' approach (Baum, 2006; Lance, et al., 2014). This procedure produces an unbiased estimation of the programme impact controlling for the endogeneity introduced by $\mu_{i}$. The estimation of the impact of SMSXXI was performed on the fraction of the population without social security (target population).

\section{ADs estimation}

Based on the impact estimates, the number of AD during the 200614 period considering the coverage levels was estimated according to the following equation:

$$
\left.\mathrm{AD}=\sum_{q=0}^{4} \frac{D_{q}}{\exp \left(\beta_{q}\right)}-D_{q}\right),
$$

where $D_{q}$ is the observed number of deaths in municipality-years contained in the $q$ th quintile of coverage and $\beta$ is the estimated impact of being in the $q$ th quintile relative to the first, after fitting the model to the data. All analyses were performed with Stata v 15.0 (StataCorp, College Station, TX, USA). All estimates with a $P$-value of $<0.05$ were considered to be statistically significant.

\section{Results}

In 2006, Mexico had 2441 municipalities corresponding to the administrative division of the 31 Mexican States, as well as 16 
Table 1 Births and neonatal and infant deaths in population without access to social security, by states of Mexico, 2006

\begin{tabular}{|c|c|c|c|c|c|c|c|c|c|c|c|c|c|c|c|}
\hline \multirow[t]{2}{*}{ State } & \multirow{2}{*}{$\begin{array}{l}\text { Number of } \\
\text { municipalities }\end{array}$} & \multicolumn{4}{|l|}{ Births } & \multicolumn{5}{|c|}{ Neonatal deaths } & \multicolumn{5}{|c|}{ Infant deaths } \\
\hline & & $n$ & Min & p50 & $\operatorname{Max}$ & $n$ & Min & $\mathrm{p} 50$ & Max & Rate per $1000 \mathrm{lb}$ & $n$ & Min & p50 & Max & Rate per $1000 \mathrm{lb}$ \\
\hline Aguascalientes & 11 & 13167 & 144 & 679 & 8074 & 94 & 1 & 3 & 55 & 7 & 148 & 2 & 5 & 86 & 11 \\
\hline Baja California & 5 & 17591 & 225 & 4150 & 8235 & 288 & 8 & 40 & 160 & 16 & 471 & 12 & 80 & 264 & 27 \\
\hline Baja California Sur & 5 & 4271 & 163 & 567 & 1825 & 45 & 1 & 4 & 20 & 10 & 65 & 1 & 9 & 27 & 15 \\
\hline Campeche & 11 & 6070 & 0 & 455 & 1481 & 49 & 1 & 2 & 15 & 8 & 76 & 1 & 6 & 21 & 13 \\
\hline Coahuila & 38 & 20138 & 0 & 102 & 6245 & 49 & 0 & 0 & 24 & 2 & 71 & 0 & 0 & 28 & 4 \\
\hline Colima & 10 & 4467 & 52 & 269 & 1258 & 65 & 0 & 5 & 18 & 14 & 86 & 0 & 6 & 27 & 19 \\
\hline Chiapas & 118 & 40731 & 0 & 191 & 3723 & 229 & 0 & 1 & 25 & 5 & 421 & 0 & 2 & 56 & 10 \\
\hline Chihuahua & 67 & 19280 & 0 & 21 & 12268 & 60 & 0 & 0 & 20 & 3 & 108 & 0 & 0 & 34 & 6 \\
\hline Distrito Federal & 16 & 44894 & 0 & 2191 & 9594 & 991 & 16 & 45 & 235 & 22 & 1513 & 26 & 70 & 356 & 34 \\
\hline Durango & 39 & 11110 & 0 & 84 & 3900 & 103 & 0 & 1 & 50 & 9 & 148 & 0 & 1 & 78 & 13 \\
\hline Guanajuato & 46 & 73000 & 65 & 881 & 15590 & 810 & 0 & 11 & 140 & 11 & 1137 & 0 & 16 & 197 & 16 \\
\hline Guerrero & 81 & 20370 & 0 & 90 & 3539 & 431 & 0 & 2 & 100 & 21 & 575 & 0 & 4 & 120 & 28 \\
\hline Hidalgo & 84 & 34570 & 0 & 284 & 3295 & 278 & 0 & 2 & 22 & 8 & 484 & 0 & 4 & 38 & 14 \\
\hline Jalisco & 124 & 71716 & 0 & 126 & 18733 & 663 & 0 & 2 & 147 & 9 & 974 & 0 & 3 & 195 & 14 \\
\hline Estado de Mexico & 125 & 218031 & 21 & 708 & 27370 & 2348 & 0 & 8 & 248 & 10 & 4011 & 1 & 14 & 395 & 18 \\
\hline Michoacán & 113 & 49120 & 0 & 212 & 4187 & 446 & 0 & 1 & 85 & 9 & 677 & 0 & 2 & 119 & 14 \\
\hline Morelos & 33 & 19410 & 54 & 306 & 3755 & 189 & 0 & 3 & 34 & 9 & 284 & 1 & 4 & 52 & 15 \\
\hline Nayarit & 20 & 11473 & 54 & 276 & 4242 & 35 & 0 & 1 & 15 & 3 & 70 & 0 & 3 & 23 & 6 \\
\hline Nuevo Leon & 51 & 24322 & 0 & 65 & 6483 & 211 & 0 & 0 & 65 & 8 & 307 & 0 & 0 & 92 & 13 \\
\hline Oaxaca & 570 & 21821 & 0 & 4 & 4176 & 130 & 0 & 0 & 10 & 5 & 221 & 0 & 0 & 14 & 10 \\
\hline Puebla & 217 & 76922 & 0 & 109 & 22036 & 1121 & 0 & 2 & 201 & 14 & 1884 & 0 & 4 & 337 & 24 \\
\hline Queretaro & 18 & 21304 & 77 & 561 & 9358 & 163 & 1 & 4 & 54 & 7 & 296 & 1 & 9 & 91 & 14 \\
\hline Quintana Roo & 8 & 13246 & 195 & 901 & 6443 & 125 & 1 & 5 & 61 & 9 & 187 & 4 & 8 & 93 & 14 \\
\hline San Luis Potosi & 58 & 25566 & 0 & 224 & 6831 & 184 & 0 & 1 & 46 & 7 & 320 & 0 & 2 & 80 & 13 \\
\hline Sinaloa & 18 & 24759 & 79 & 690 & 6872 & 161 & 1 & 4 & 55 & 6 & 214 & 1 & 5 & 66 & 9 \\
\hline Sonora & 72 & 16663 & 0 & 18 & 4229 & 136 & 0 & 0 & 33 & 8 & 262 & 0 & 0 & 72 & 16 \\
\hline Tabasco & 17 & 33281 & 458 & 1495 & 9389 & 229 & 1 & 8 & 68 & 6 & 360 & 2 & 13 & 100 & 11 \\
\hline Tamaulipas & 43 & 30773 & 3 & 195 & 6340 & 251 & 0 & 1 & 44 & 8 & 341 & 0 & 1 & 67 & 11 \\
\hline Tlaxcala & 60 & 15383 & 0 & 141 & 2108 & 193 & 0 & 2 & 18 & 12 & 318 & 0 & 3 & 36 & 21 \\
\hline Veracruz & 212 & 63212 & 0 & 143 & 6300 & 789 & 0 & 2 & 61 & 12 & 1191 & 0 & 3 & 77 & 19 \\
\hline Yucatan & 106 & 16302 & 0 & 42 & 3997 & 154 & 0 & 0 & 48 & 9 & 252 & 0 & 1 & 72 & 15 \\
\hline Zacatecas & 58 & 17791 & 8 & 131 & 2124 & 170 & 0 & 1 & 34 & 9 & 253 & 0 & 2 & 50 & 14 \\
\hline
\end{tabular}

precincts (delegaciones) within the Federal District. Among the states, there is a great diversity in terms of the concentration of municipalities; the northern states of Baja California and South Baja California are each divided into five municipalities, while the southern state of Oaxaca has the record high of 570. In fact, only five states concentrate more than half the municipalities in the country: Oaxaca (570), Puebla (217), Veracruz (212), Jalisco (125) and the State of Mexico (125) (Table 1).

According to the population census of 2010, Mexico had a population of 112.3 million inhabitants, of which $56 \%$ lived in one of the 56 major metropolitan areas; $80 \%$ of urban dwellers did in fact live in one of those areas. Population density was also highly variable: Ecatepec in the State of Mexico was the most populated municipality in Mexico and Latin America with almost three million residents and almost 11000 inhabitants per square kilometre; on the other extreme, the municipality of Santa Magdalena Jicotlán, Oaxaca, had only 100 residents.

Approximately 2.2 million children are born annually in Mexico, of whom $\sim 60 \%$ do not have social security at the moment of birth. Among the municipalities, births also exhibit great heterogeneity, with a minimum of 0 and a maximum of 32105 annual births, with a mean of 230 . The lack of social security is also highly variable, with municipalities with $>80 \%$ affiliation to social security, although in all the states of the country there is at least one municipality where $<10 \%$ of the children are born with social security.
It is clear that the lack of access is higher in the centre and south of the country, although the quality of information is not homogeneous: the percentage of births in which it was impossible to determine whether there was access to social security ranges from $1 \%$ to $67 \%$, with the greatest deficiencies occurring in remote municipalities of Oaxaca, Chiapas, Hidalgo and the State of Mexico.

In 2014, SMSXXI had $\sim 5.6$ million beneficiaries distributed throughout the country. The municipalities with the greatest relative number of beneficiaries are generally in the states of Jalisco and Oaxaca, reaching 19 and 20 beneficiaries per 1000 inhabitants without social security, respectively. On the other hand, Colima and Campeche barely pass 10 beneficiaries per 1000 inhabitants without social security. The ratio of beneficiaries to uninsured population showed an increasing trend up to the year 2012, but it decreased in 2013 and 2014; this should be cautiously interpreted as it could be due to changes in the denominator (population without access to health insurance).

Regarding child mortality, huge variations between municipalities were observed. In 2006, the neonatal mortality rate in the target population was 8.70 per 1000 live births, whereas the infant mortality rate was 14.18 per 1000 live births. The distribution of both indicators in population without access to social security does not fully match the distribution observed in the general population: Mexico City (formerly the Federal District) appeared in 2006 in the first place in both infant and neonatal mortality ( 34 and 22 deaths per 


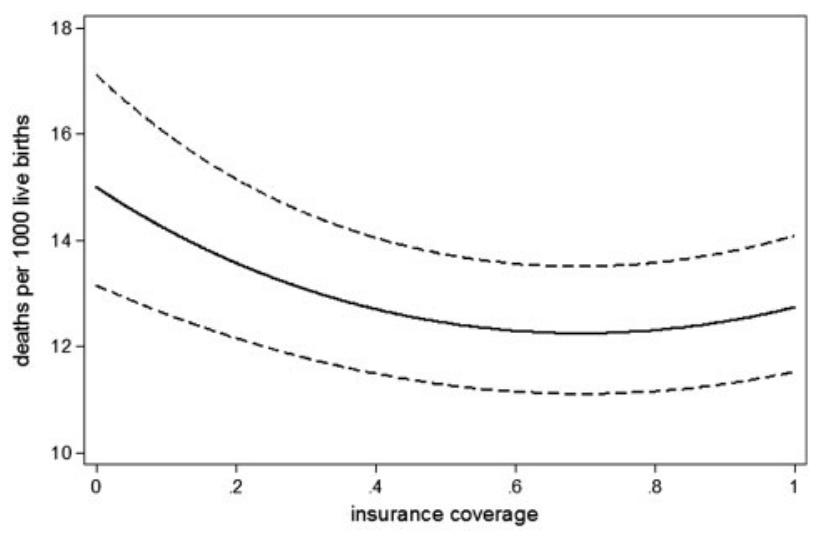

Figure 1 Insurance coverage and neonatal mortality in population without access to social security, for a typical municipality in Mexico, mid-period 200614. Adjusted for time trend, education and occupation rates, the number of health personnel and age structure of mothers in the municipality. Dotted lines are $95 \%$ confidence bands.

1000 live births, respectively), followed by Guerrero and Puebla. In 2014 , infant mortality had decreased nationally to 11.16 deaths per 1000 live births and neonatal mortality to 6.83 deaths per 1000 live births, with Chihuahua now appearing in the first place of infant mortality ( 15.50 deaths per 1000 live births), followed by Tabasco and the State of Mexico. Tabasco (9.56 deaths per $1000 \mathrm{lb}$ ), Chihuahua and Coahuila occupied the first three spots, respectively, in neonatal mortality in 2014. Oaxaca, Sonora and Yucatan contained the municipalities with the greatest death rate, reaching 500, 333 and 100 deaths per 1000 live births, respectively (although it is important to state that these parameters are highly volatile due to the small number of births in these locations). No municipality contained in the states of Nayarit, Sonora, Colima and Baja California went $>10$ deaths per 1000 live births. Complete state-level statistics on infant and neonatal deaths in the target population during the year 2006 are presented in Table 1 and in a Supplementary Table for the year 2014.

Regarding the SMSXXI coverage, the nation-wide increase between 2008 (the first year with detailed coverage statistics after implementation in 2007) and 2014 was 55.4 percentage points. States such as Queretaro, San Luis Potosi and Guanajuato had increases in the coverage of $>63$ percentage points. In most states, 2014 coverage levels were $>80 \%$.

SMSXXI impact estimates on the neonatal and infant mortality rates of the target population appear in Figure 1 and Table 2 for the continuous and quintile coverage models, respectively. According to the coverage level, results show that SMSXXI reduces infant mortality rates in the target population, although the effect is significantly non-linear. After adjusting for covariates and the time trend in mortality rates, we see that the minimum infant mortality was reached when coverage levels were $\sim 70 \%$, with a reduction of $\sim 13.3 \%$ comparing to $0 \%$ coverage. Under the coverage quintiles approach, a hypothetical transition from the first quintile to the fourth quintile of coverage (under $12.5 \%$ to $70-94 \%$ coverage) would yield a $9.7 \%$ reduction in infant mortality rates resulting in 3.47 deaths per 1000 live births been avoided, whereas a transition from the first quintile to the fifth quintile ( $>94 \%$ coverage) would translate into a nonsignificant $5.4 \%$ decrease, resulting in 1.76 ADs per 1000 live births occurred during the period.

A significant impact was also found on neonatal mortality rates during the study period, of comparable magnitude to the impact on infant mortality: a non-linear functional form is also evident, with a minimum at $\sim 70 \%$ coverage, reaching a $13 \%$ reduction in mortality relative to $0 \%$ coverage. Under the coverage quintile approach, a hypothetical transition from the first quintile to the fourth quintile of coverage would translate into a $8.1 \%$ reduction in the neonatal mortality rate, with 1.72 neonatal deaths been avoided per 1000 live births. As in the infant mortality model, a transition from the first quintile to the fifth quintile of coverage yields a risk reduction smaller than that of the first-fourth quintile transition $(2.5 \%$ reduction in neonatal mortality), which is no longer statistically significant. The reduction in effect size in the fifth quintile relative to the fourth was statistically significant at the 0.05 level for both the infant and neonatal mortality models $(P=0.029$ and $P=0.030$, respectively).

\section{Discussion}

We found a significant impact of the programme on both infant and neonatal mortality in Mexico, with more than 11000 deaths avoided during the period, with about half of these $(48 \%)$ being neonatal. Both models show a smaller risk reduction in the fifth quintile of coverage relative to the fourth, which even becomes nonsignificant relative to the lowest levels of coverage. An independent group of researchers following a different approach recently reported a significant impact of SMSXXI on late neonatal and infant mortality, although they did not seem to have tested for non-linear programme effects, nor tried to estimate impact only in the target population (Celhay et al., 2019). Sosa-Rubi et al. (2009) discovered that 'Seguro Popular' increases the percentage of births attended in participant clinics at the expense of non-certified and private ones. If the number of users is increasing by the effect of the insurance, the observed diminishing returns of the increase in coverage and eventual regression to higher levels of mortality may reflect overcrowding of health services with a consequent detriment in the quality of care that offsets gains achieved by increased use of health services, as has been documented in other settings (Sun et al., 2013); a recent study in Kenia versed on the link between infant mortality and overcrowding of health services (Murphy et al., 2018). Although Celhay et al. (2019) did not find an effect of the insurance on the number of hospitalizations, a plausible increase in the utilization (and overcrowding) of primary care units was not evaluated; overcrowding in the first level of care could translate into a poorer quality of antenatal care. Our findings might then reflect insufficient resources to meet increasing demand in services, especially in poor, remote areas of the country [Mexico has one of the lowest health expenditures in health within OECD members (OECD, 2015)].

The finding that Mexico City was in first place in mortality in the target population in 2006 is striking. We could not find previous published estimates of infant or neonatal mortality specifically in population without access to social security in Mexico; thus, we have nothing to compare against. As our figures do not represent mortality as a whole but rather on population who usually seeks care in Ministry of Health $(\mathrm{MOH})$ hospitals, these findings could signify that infant care in $\mathrm{MOH}$ hospitals of Mexico City was very deficient prior to the implementation of the SMSXXI. In fact, in Mexico City, in 2006, most deaths occurred in children without access to social security, while a minority of births occurred in $\mathrm{MOH}$ hospitals, where those without SS seek care, especially those in the lowest socio-economic class. It is perhaps worth mentioning that $\mathrm{MOH}$ hospitals are traditionally under-staffed and under-equipped, which was especially true in the years before the implementation of 
Table 2 Impact of the SMSXXI on neonatal an infant mortality rates in the target (without access to social security) population, Mexico 2006-14. The models are fixed effects adjusting for time trend, education and occupation rates, and age structure of mothers in the municipality

\begin{tabular}{|c|c|c|c|c|c|}
\hline & \multirow{2}{*}{$\begin{array}{l}\text { SMSXXI coverage } \\
(\%)\end{array}$} & \multicolumn{2}{|l|}{ Infant mortality } & \multicolumn{2}{|l|}{ Neonatal mortality } \\
\hline & & IRR (SE) & $\begin{array}{l}\text { Avoided deaths } \\
\text { per } 1000 \mathrm{lb}^{\mathrm{a}}\end{array}$ & IRR (SE) & $\begin{array}{l}\text { Avoided deaths } \\
\text { per } 1000 \mathrm{lb}^{\mathrm{a}}\end{array}$ \\
\hline Coverage SMSXXI (first quintile, reference) & $0.0-12.5$ & 1 & & 1 & \\
\hline Coverage SMSXXI (second quintile) ${ }^{\mathrm{b}}$ & $12.5-42.4$ & $0.928(0.019) * * *$ & 2.97 & $0.931(0.022)^{* * * *}$ & 1.75 \\
\hline Coverage SMSXXI (third quintile) ${ }^{\mathrm{b}}$ & $42.4-70.5$ & $0.914(0.028)^{* * *}$ & 3.16 & $0.934(0.034)^{*}$ & 1.48 \\
\hline Coverage SMSXXI (fourth quintile) ${ }^{\mathrm{b}}$ & $70.5-93.7$ & $0.903(0.032) * * *$ & 3.47 & $0.919(0.039)^{* * *}$ & 1.72 \\
\hline Coverage SMSXXI (fifth quintile) ${ }^{\mathrm{b}}$ & $93.7-100$ & $0.946(0.036)$ & 1.76 & $0.975(0.045)$ & 0.48 \\
\hline Observations & & \multicolumn{2}{|c|}{20669} & \multicolumn{2}{|c|}{19882} \\
\hline Number of municipalities & & \multicolumn{2}{|c|}{2337} & \multicolumn{2}{|c|}{2246} \\
\hline
\end{tabular}

'In the whole period; counterfactual scenario on the basis of actual yearly coverage levels.

${ }^{\mathrm{b}}$ Change from the first quintile of coverage.

$* P<0.1$.

$* * P<0.05$.

$* * * P<0.01$.

IRR: incidence rate ratio; SE: Standard Error.

the Seguro Popular (Barraza-Lloréns et al., 2002). On the contrary, in states like Oaxaca, data show that most infant deaths in 2006 occurred in children with access to social security while a clear majority of births was from mothers without social security. One could argue that the reason why Mexico City and Nuevo Leon are traditionally better than Oaxaca and Chiapas is because more people there have access to social security, but those who do not have access to it are actually much worse in these states than people in the poorest states (at least this could be the case back in 2006). These findings could also imply that the quality of services offered by social security providers is not at all homogeneous throughout the country, with states such as Oaxaca where children with access to these institutions were actually at a greater risk than those cared for at the $\mathrm{MOH}$. More research on inequities between the multiple Mexican health sub-systems in different regions of the country is needed to clarify these findings.

Child mortality levels decreased in the study period, and the reasons underlying these decreases are surely multifactorial and deserve further study, although it seems clear that the SMSXXI has indeed played a role in decreasing mortality in the target population. In our study, we controlled for time invariant differences between municipalities that might be related to the environment or other fixed attributes. Unobserved factors have undoubtedly a great role in the determination of child mortality; understanding the local policy factors associated with variations in mortality could provide important insights and opportunities for shared learning. Nevertheless, our models provided strong evidence of an impact of the insurance, and calls to support the continued investment in the main determinants of lower child mortality, namely maternal education, employment and the development and application of new technologies. The dominant health focus on the improvement of child survival in Mexico has been successful, although more remains to be done.

This analysis has several limitations. First, we attempted to model the effect of time-invariant covariates by the use of a fixed-effects regression model using a panel of municipalities. This approach avoids estimation of false trends due to compositional bias in the data available for a given year but depends on the extent to which these covariates are indeed fixed and not time-varying. Other secular trends acting on determinants not included in the model are unaccounted for and may still introduce bias on the impact estimates, although we tried to control by this by modelling the time trend itself. Specifically in the case of the Oportunidades/PROSPERA programme, we were actually able to identify and include a municipal-level coverage variable, but it did not show a significant impact on mortality nor it noticeably changed the insurance impact estimates. Second, the study has an ecological approach, which has the fundamental limitation of being unable to establish a causal relationship at the individual level. Third, measurement error of infant and child mortality rates due to subregistration especially in remote municipalities is possible. This probably coincides with regions of low coverage, which may bias estimates, although the extent of the bias might not be as large as to change the broad conclusions of this study due to small numbers in these regions. Regardless, if we assume that underreporting remains more or less constant over time (which would be the case if underreporting depends on factors such as accessibility to health services, for example), the fixed-effects nature of the model should correct for it. The affiliation rate might also be measured with error, likely coming from the denominator, as annual municipal numbers of the target population are estimates. We have, however, no reason to think that these errors are differential; therefore, under the classical measurement error model, the effect estimates are likely biased towards the null value (Hyslop and Imbens, 2001).

In conclusion, we found a considerable impact of the SMSXXI programme on infant and neonatal mortality in Mexico. The fact that the impact is reduced at very high levels of coverage point to a possible insufficiency of health services to deal with increased demand. As post-2014 the programme reached nearly universal coverage of its target population, eyes should be turned to the unresolved issue of quality of care in Mexican public clinics and hospitals.

\section{Supplementary data}

Supplementary data are available at Health Policy and Planning online.

\section{Acknowledgement}

This study was funded by the 'Comisión Nacional de Protección Social en Salud', under project RPCISP/1502.

Conflict of interest statement. 
G.O., V.M.V., E.H. and V.D.-S., were at the time of this analysis with the 'Comisión Nacional de Protección en Salud', which was responsible for the implementation of the Seguro Médico Siglo XXI.

Ethical approval. The study was approved by the Ethics Committee of the National Institute of Public Health of Mexico (authorization number CI: 1346, No. 1731).

\section{References}

Baum C. 2006. An Introduction to Modern Econometrics Using Stata. College Station, TX: Stata Press, 220-31.

CAUSES. 2019. http://www.documentos.seguro-popular.gob.mx/dgss/CAUSES_ 2018c.pdf, accessed 29 May 2019.

Barraza-Lloréns M, Bertozzi S, González-Pier E, Gutiérrez JP. 2002. Addressing inequity in health and health care in Mexico. Health Affairs 21: 47-56.

Celhay P, Martinez S, Muñoz M, Perez M, Perez-Cuevas R. 2019. Long-term effects of public health insurance on the health of children in Mexico: a retrospective study. The Lancet Global Health 7: e1448-57.

Comisión Nacional de Protección en Salud. 2019a. https://www.gob.mx/salud $\% 7 C$ seguropopular/acciones-y-programas/enfermedades-de-alto-costo, accessed 29 May 2019.

Comisión Nacional de Protección en Salud. 2019b. https://www.gob.mx/salud

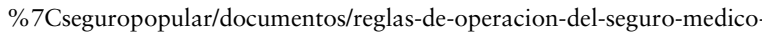
siglo-xxi-para-el-ejercicio-2018, accessed 29 May 2019.

Flores-Huerta S, Klünder-Klünder $\mathrm{M}$, Martínez-Valverde S, MuñozHernández O. 2014. An approximation to data on mortality and out-of-pocket expenses for medical attention of infants $<2$ years old affiliated with the Medical Insurance Siglo XXI. Boletin medico del Hospital Infantil de Mexico 71: 271-6.

GBD 2015 Child Mortality Collaborators. 2016. Global, regional, national, and selected subnational levels of stillbirths, neonatal, infant, and under-5 mortality, 1980-2015: a systematic analysis for the Global Burden of Disease Study 2015. The Lancet 388: 1725-74.

Hyslop DR, Imbens GW. 2001. Bias from classical and other forms of measurement error. Journal of Business \& Economic Statistics 19: 475-81.
IHME. 2016. GBD Compare Data Visualization. Seattle, WA: IHME, University of Washington. http://vizhub.healthdata.org/gbd-compare, accessed 11 October 2018 .

Lance P, Guilkey D, Hattori A, Angeles G. 2014. How Do We Know If a Program Made a Difference? A Guide to Statistical Methods for Program Impact Evaluation. Chapel Hill, NC: MEASURE Evaluation, 149-201.

Murphy GAV, Gathara D, Abuya N et al.; on behalf of the Health Services that Deliver for Newborns Expert Group. 2018. What capacity exists to provide essential inpatient care to small and sick newborns in a high mortality urban setting?-A cross-sectional study in Nairobi City County, Kenya. PLoS One 13: e0196585.

OECD. 2019. https://data.oecd.org/healthres/health-spending.htm, accessed 29 May 2019.

PAHO. 2008. Estrategia y plan de acción regionales sobre la salud del recién nacido en el contexto del proceso continuo de la atención de la madre del recién nacido $y$ del niño. https://www.paho.org/clap/index.php?option=com_docman\& view document\&layout=default\&alias=138-estrategia-y-plan-de-accion-regionalessobre-la-salud-del-recien-nacido-2\&category_slug=recursos-estrategicos-aten cion-materna-y-neonatal\&Itemid=219\&lang=es, accessed 29 May 2019.

Pfutze T. 2014. The effects of Mexico's Seguro Popular Health Insurance on infant mortality: an estimation with selection on the outcome variable. World Development 59: 475-86.

Reyes-López A. 2014. Does the Medical Insurance Siglo XXI have the potential to reduce neonatal and under-5 mortality rate in Mexico? Boletin medico del Hospital Infantil de Mexico 71: 259-60.

Royston P, Sauerbrei W. 2008. Multivariable Model-Building: A Pragmatic Approach to Regression Analysis Based on Fractional Polynomials for Modelling Continuous Variables. Chichester: Wiley.

Sosa-Rubi SG, Galarraga O, Harris JE. 2009. Heterogeneous impact of the "Seguro Popular" program on the utilization of obstetrical services in Mexico, 2001-2006: a multinomial probit model with a discrete endogenous variable. Journal of Health Economics 28: 20-34.

Sun BC, Hsia RY, Weiss RE et al. 2013. Effect of emergency department crowding on outcomes of admitted patients. Annals of Emergency Medicine 61: 605-11.e6.

WHO. 2018. Levels and trends in child mortality. Report 2018. https://child mortality.org/reports, accessed 29 May 2019. 